\title{
Emerging Applications and Future Roles of Nanotechnologies in Agriculture
}

\author{
Hendrickson $\mathrm{C}^{1 *}$, Garett Huffstutler ${ }^{1}$ and Bunderson $\mathrm{L}^{2}$ \\ ${ }^{1}$ Department of Mathematics and Natural Sciences, National University, USA \\ ${ }^{2}$ Aqua Yield Operations, USA
}

Submission: August 17, 2017; Published: August 29, 2017

"Corresponding author: Hendrickson C, Department of Mathematics and Natural Sciences, National University, 11255 North Torrey Pines Rd. La Jolla California, 92037, USA, Email: chendrickson@nu.edu

\begin{abstract}
Faced with decreased access to arable land, freshwater resources, increasing populations and increased regulatory pressures, new tools are needed to ensure sustained agricultural production. Nanoparticle technologies have begun to be deployed in agricultural applications, with diverse, powerful results. Of these, bioactive metal and biopolymer-based chemistries have emerged as the first-generation nanoparticle technologies for use in agriculture, with crop responses reported from tests in greenhouse-controlled and field-based studies. Next-generation nanoparticle technologies are emerging incorporating variability in internal pore space, surface porosity and surface chemical adsorptive properties that indicate a significantly improved capacity to adsorb, contain and ultimately deliver phytonutrients, and various agrochemicals into plant tissues. Both foliar and root zone applications have suggested that nanoparticle inherent properties alone can trigger an array of beneficial responses in target crops. However, with the increasing structural and chemical diversity exhibited in such next-generation technologies, nanoparticle uptake, mobility and even biodegradability are being tuned to address challenges in crop production. This brief review highlights the rapidly moving frontiers in agricultural nanoparticle technology, with a focus on opportunities for immediate application in the field.
\end{abstract}

Keywords: Nanotechnology; Agriculture; Sustainability; Fertilizers

Abbreviations: NP: Nanoparticle, CuNP: Copper Nanoparticle; CNP: Chitosan Nanoparticle

\section{Introduction}

Nanoparticles (NPs) are considered any under $1.0 \mu \mathrm{m}$. Despite this simple classification, there exist a broad, rapidly expanding array of particle geometries, porosities, surface chemical properties and chemical compositions in research and commercial contexts in agricultural use. Nanoparticles display vastly different properties than those of their larger bulk counterparts. Large specific surface area has been shown to affect nutrient absorption, improve biotic stress resistance and enable reduced raw amounts of agrochemical active ingredients [1-4]. These can provide both direct and indirect benefits, including reduced production costs through reduced agrochemicals applied, reduced application frequency and reduced environmental impact. Nanoparticles can also be formulated to 'carry' or adsorb additional desired agrochemical compounds via hollow pore-space or surface channels. These unique properties allow for many agricultural applications. From this diversity, NPs have elicited a broad array of responses in crops suggesting more exhaustive characterization of NP properties is needed to reliably predict how their use in agriculture may be optimized. Modern use of NP technology in agriculture is almost exclusively restricted to the research community, though this is expected to change in the coming years.

While a complete understanding of these responses in target crops remains, there is already impetus to begin adoption of NP technologies into various agricultural contexts. For example, Chandra et al. [5] observed significant improvements in immune response of plants treated with chitosan NPs [5]. Improvements have also been observed in the control of phytopathogens as well as abiotic stress response, nutrient delivery as well as growth and yield responses [1,2,6-8].

Research has also begun to characterize crop responses from applications of metallic and biopolymer-based NPs, including zinc, copper, chitosan and modified compositions with one or more of these constituents and the use of NPs as agrochemical delivery systems [1,8-13]. These 'first-generation' NP technologies have revealed powerful bioactive properties of the particles alone, 
without additional agrochemical 'payload'. The high surfacearea-to-volume ratio and nano-scale particle size allows for NPs to have greater contact with soil colloids, mineral complexes, root tissues and microorganisms in the rhizosphere. Zinc and copper oxide as well as silver-based NPs are also soluble in aqueous conditions, integrating easily with existing fertilization regimes. Inherent surface chemical properties (measured in -potential), can generate increased antimicrobial activity through disruption with neighboring membrane stability, possibly impacting other cellular processes [14]. Additionally, NPs internal pore-space, surface porosity and other properties increase the efficiency of nano-scale preparations of pesticides due to the large specific surface area along with an increased rate of decomposition in soil [3].

Uptake, mobility, and translocation of NPs in crop tissues varies do to the toxicity of the NPs, the composition of the cell wall, and mode of transport [15]. Accumulation of non-toxic NPs is generally proportional to the exposure concentration and plants with lower transpiration rates were found to translocate less NPs. Based on these initial findings, NP uptake appears to be affected by chemical composition, size, and plant-derived factors. As this technology continues to expand in the agricultural market, much more research will be needed to identify limitations of specific particles' uptake by crops.

Some novel NP design and fabrication has centered around biodegradability upon exposure to, or uptake by target cells. Additional studies in NP engineering have indicated numerous chemical approaches to generate biodegradable technologies. This can open the possibility of loading such NPs with desired active chemistries, for uptake and some degree of translocation in apoplastic or cytoplasmic space. Some mobility of NPs has been reported in pumpkin, though other has also shown no mobility at all in maize [16-17]. Amino acid composition biodegradability. Proline and modified-amino acid based chemistries have also been utilized in designs toward a specific aim of protein 'carrying', followed by nanoparticle metabolism and ultimate biodegradability in target cells. Copolymers composed of amphiphilic amino acids and hydrophobic compounds have successfully been formed into biodegradable NPs [18]. These copolymer NPs were able to successfully encapsulate proteins and prevent damage to the proteins during freeze-drying. Their agricultural applications have been limited due the presence of a cell wall. However, mesoporous silica nanoparticles have successfully transported DNA and chemicals into plant cells [1]. Solid lipid NPs can also be useful as pesticide delivery systems [19]. An essential oil derived from Artemisia arborescens has demonstrated strong antifungal and antibacterial activity yet is difficult to deliver because of its chemical instability. However, when encapsulated in a solid lipid NP this ecological pesticide can be successfully delivered and evaporation of the essential oil can be minimized. Despite these reports of a payload-delivering, biodegradable NP in a eukaryotic cell, the same properties can be exploited in plants.
While currently subject to little regulation from dominant agricultural regulatory bodies around the world, mitigating accumulation of NPs in crops for human or animal consumption can provide marketability advantages for NP, agrochemical and crop producers. This may be a critical component of developing next-generation NPs specifically for use in agriculture, as some data suggests threshold levels of NPs in fruit tissues can impact ripening progress and overall fruit quality [14].

\section{Crop Immune Responses and Phytopathogen Control}

Many metallic NPs are potentially useful against phytopathogens due to their antimicrobial and antifungal properties. Increased bioactivity due to large specific surface area allows for the conservative use of these compounds thus, minimizing phytotoxicity. For instance, copper is known to exhibit antimicrobial properties. To that end, Kanhed et al. [2], reported a multi-fold enhancement of antifungal activity of CuNPs against plant pathogenic fungi when compared to bulk copper (Figure 1).

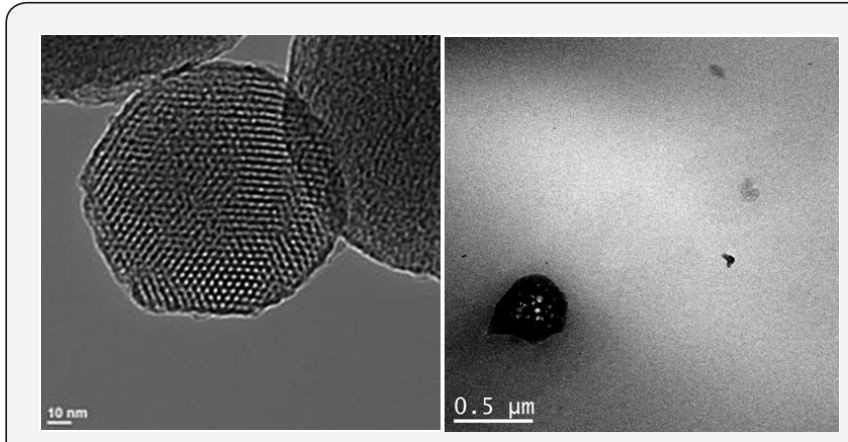

Figure 1: Porous nanoparticles for enhanced delivery of agrochemicals to crop tissues. (Left) Mesoporous silica nanoparticle with internal pore space, under $100 \mathrm{~nm}$ diameters. This nanoparticle porosity can be altered through processes of synthesis or modification to allow for 'loading' of desired agrochemical products, including fertilizers, growth regulators, pesticides, biostimulants and more. Image courtesy Creative Commons license. (Right) larger, 500nm diameter semi-vitreous, silicon oxide nanoparticle with light visibly passing through the internal space of the nanoparticle, indicating hollow morphology. The internal space appears to be 'caged' by a porous, nanoparticle exterior. Image courtesy Aqua Yield Operations, LLC (Draper, UT USA).

The biopolymer, chitosan, is known to boost immune response in plants, but when constructed as a chitosan nanoparticle (CNP) it elicits enhanced responses to biotic stressors. Treatment of Camellia sinensisleaf tissues with CNP produced higher defense enzyme activity, an increase in antioxidant enzymes and increased levels of phenols and flavonoids, than treatments with chitosan [5].

\section{Abiotic Stress Responses}

Numerous studies suggest plant silicon and silicate have a positive role in ameliorating salt and drought stress. When prepared at the nano-scale, silica NPs have been shown to increase drought tolerance by encouraging retained 
photosynthetic rates and stomatal conductance under moderate and severe drought stress [6]. This work also showed that Hawthorn (Cretaegus sp.) seedlings pre-treated with silica NPs have increased photosynthetic rates and stomatal conductance, as well as increased xylem water potential under drought stress. These findings align with a growing body of evidence suggesting various silicon/silica application can improve abiotic stress tolerance in numerous crop species [20]. Rates of application in silica agrochemical products range from $10 \mathrm{mgl}^{-}$ ${ }^{1}$ to $100 \mathrm{mgl}^{-1}$, while Ashkavand et al. [6], found rates of active ingredient as low as $10 \mathrm{mgl}^{-1}$ can elicit powerful benefits toward stress tolerance improvement in Hawthorne. It is reasonable to attribute the improved performance of silica nanoparticleinclusive agrochemical products due to improved uptake and/or penetration into crop tissues, however more study is needed to clarify the specific role of nano-scale application.

\section{Nutrient and Agrochemical Delivery}

Higher efficiency pesticides and fertilizers are desperately needed to decrease contamination and toxicity within the environment. Currently, excess amounts of pesticides and fertilizers must be applied due to the vast majority being lost through evaporation, drying, and photodegradation. To address this problem, NPs have been used to encapsulate and 'load' these compounds into the particles' internal pore space, allowing them to reach their target. The structures of NPs can be specifically tailored to the compound it carries to allow for a controlled, targeted release of the compound [8]. Nano-scale formulations of macronutrients such as nitrogen, phosphorus and potassium have increased efficiency thus reducing the amount of fertilizer used [1]. Similarly, Cota-A et al. [7], showed that by encapsulating copper with chitosan, its release can be controlled by the density of the chitosan polymer matrix. Thus, mesoporous particle properties allow for improved uptake and penetration in to crop tissues through surface-chemical properties can also lead to increased agrochemical adsorption. As size, internal pore-space, surface porosity and biodegradability are further optimized in next-generation NP technologies, these efficiency gains will likely continue to rise (Table 1).

Table 1: Summary of reported nanoparticle-based agricultural technologies, chemical composition, crop species and tissue tested and broad responses. ${ }^{* *}$ : Includes combined biochar-iron and other metal micronutrient technologies. $\dagger$ : And associated silicon-containing derivatives. ${ }^{*}$ Includes combined chitosan technologies.

\begin{tabular}{|c|c|c|c|c|}
\hline Composition & Crop(s) Tested & Tissue(s) Tested & Observed Responses & Reference(s) \\
\hline Zinc oxide & Arachis hypogaea & Seed & Enhanced seed germination and seedling vigor & [9] \\
\hline Copper* & Zea mays & Seed & $\begin{array}{c}\text { Increased shoot, length, root length, root number, } \\
\text { hypocotyl length, fresh weight,and SVI were } \\
\text { recorded in } 0.04,0.08 \text {, and } 0.12 \% \mathrm{Cu} \text {-chitosan, } \\
\text { NPs treated seeds }\end{array}$ & {$[9]$} \\
\hline Silver & Sorghum bicolor & Seedling & Decreased root length, necrosis & {$[21]$} \\
\hline Silica oxide $†$ & Cretaegus sp. & Seedling & $\begin{array}{c}\text { Increased photosynthetic rate, stomatal } \\
\text { conductance, and xylem water potential under } \\
\text { drought stress }\end{array}$ & {$[6]$} \\
\hline Chitosan & Camellia sinensis & Leaves & $\begin{array}{l}\text { Increased activity of defense enzymes, } \\
\text { antioxidant, phenol and flavonoid levels }\end{array}$ & {$[5]$} \\
\hline Biochar** & $\mathrm{N} / \mathrm{A}$ & $\mathrm{N} / \mathrm{A}$ & Increased grain yield, and $\mathrm{N}$ use efficiency & {$[22]$} \\
\hline Zeolite & $\mathrm{N} / \mathrm{A}$ & $\mathrm{N} / \mathrm{A}$ & $\mathrm{N} / \mathrm{A}$ & {$[23]$} \\
\hline$\gamma$-Glutamic acid* & $\mathrm{N} / \mathrm{A}$ & $\mathrm{N} / \mathrm{A}$ & $\mathrm{N} / \mathrm{A}$ & {$[24-26]$} \\
\hline $\begin{array}{l}\text { Lecithin-stabilized } \\
\text { tetracosane lipid- } \\
\text { mycelle }\end{array}$ & $\mathrm{N} / \mathrm{A}$ & $\mathrm{N} / \mathrm{A}$ & $\mathrm{N} / \mathrm{A}$ & {$[12]$} \\
\hline
\end{tabular}

\section{Growth and Yield Responses}

Significant opportunities exist to further leverage the growing diversity of nanoparticle chemical compositions, and preparations to affect growth and yield of plants. The vast majority of such technologies appear targeted toward the medical therapeutics, pharmaceutical and food science industries. Translational studies of these well-characterized technologies may enable solutions to long-standing, recalcitrant challenges in crop production. For example, poorly soluble phosphatidic acids have recently been reported stimulate root hair and secondary root growth in plants [21]. Through pairing with agricultural emulsifiers, wettings agents or simply be deployed in purely aqueous solutions to deliver bioactive hydrophobic chemistries in cost-effective approaches through loading of agrochemicals into porous NPs' internal space. There exists significant opportunities to leverage NP technologies with the evolving knowledge of plant biochemical responses to modulate crop growth.

The effects of NPs on growth and yield have been widely studied. These effects are largely dependent on plant species, 
type of NP, and concentration of NP. Application of carbon nanotubes to datein palm cultures significantly increased fresh weight, germination, root number and growth vigor [22]. Prasad et al. [9] reported silver NPs promote seed germination and seedling vigor of peanuts. Positive effects have also been shown for Cu-chitosan NPs and TiO2 NPs [10-11]. Further studies are needed to assess optimum levels of NP application as well as toxicity to non-target plants [23-25].

\section{Conclusion}

While still in relative infancy, emerging nanotechnologybased products are commanding significant attention in the agricultural field. A growing body of research has shown NPs can enable significant reductions in raw amounts of agrochemicals and application frequency in broad agricultural production systems. These technologies pair well with existing irrigation and agrochemical delivery infrastructure, including fertigation, tank-spraying, fogging, etc., common in the majority of production contexts ranging from large-scale grain, to specialty crop systems. These results suggest inclusion of NP technology into production regimes will require little modification, and will result in reduced environmental and financial impact from agricultural operations. These compounded benefits will inevitably lead to widespread adoption of such technologies as they become better understood and more accessible [26-28].

Overall, responses in both foliar and root zone applications to target crops suggests that nanoparticle size, chemical composition, porosity, surface chemical properties and additional aspects of each unique NP technology are critical determinants toward their application. This suggests significant future study is needed to characterize tissues' responses at various levels, including transcriptomic, proteomic, metabolomics, nutrient content and numerous other contexts before these diverse technologies are reliably deployed in large-scale agriculture. Further, the diverse responses observed among various NP types may foretell narrow, tissue, or site-specific optimal use. Additionally, use of particular NP types may be best paired to unique stages of crop ontogeny, periods of abiotic stress, or biotic pressures. While largely unregulated by dominant agricultural bodies around the world, more work is needed to understand impacts of NPs in crops for the food chain, including postharvest study. This needed research will undoubtedly emerge from the agricultural community as the promise and potential pitfalls of these technologies begin to be both better understood, and more widely known. Perhaps most importantly, all agricultural NPs reviewed so far, and many with medical or food-science industry origins can be easily integrated into existing crop production infrastructure, requiring either agitation, emulsifiers or both.

\section{Acknowledgement}

Thanks are extended to Warren Bell and Roger Kjelgren for critical reading of the manuscript.

\section{References}

1. Chhipa H (2017) Nanofertilizers and nanopesticides for agriculture. Environ Chem Lettttrs 15(1): 15-22.

2. Kanhed, P, Birla S, Gaikwad S, Gade A, Seabra AB, et al. (2014) In vitro antifungal efficacy of copper nanoparticles against selected crop pathogenic fungi. Materials Lettrs. 115: 13-17.

3. Khot LR, Sankaran S, Maja JM, Ehsani, R, Schuster EW (2012) Applications of nanomaterials in agricultural production and crop protection: a review. Crop Prot 35: 64-70.

4. Torney F, Trewyn BG, Lin VSY, Wang K (2007) Mesoporous silica nanoparticles deliver DNA and chemicals into plants. Nature Nanotechnol 2(5): 295-300.

5. Chandra S, Chakraborty N, Dasgupta A, Sarkar J, Panda K, et al. (2015) Chitosan nanoparticles: a positive modulator of innate immune responses in plants. Sci Rep 5:15195.

6. Ashkavand P, Tabari M, Zarafshar M, Tomášková I, Struve D (2015) Effect of SiO2 nanoparticles on drought resistance in hawthorn seedlings. For Res Pap For Res Papers 76(4): 350-359.

7. Cota AO, Cortez-RMO, Burgos-HA, Ezquerra-BJM, Plascencia-JM (2013) Controlled release matrices and micro/nanoparticles of chitosan with antimicrobial potential: development of new strategies for microbial control in agriculture. J Sci Food Agric 93(7): 1525-1536.

8. Sabir S, Arshad M, Chaudhari SK (2014) Zinc oxide nanoparticles for revolutionizing agriculture: synthesis and applications. Sci World ] 2014: 925494.

9. Prasad TNVKV, Sudhakar P, Sreenivasulu Y, Latha P, Munaswamy V, et al. (2012) Effect of nano-scale zinc oxide particles on the germination, growth and yield of peanut. J Plant Nut 35(6): 905-927.

10. Saharan V, Kumaraswamy RV, Choudhary RC, Kumari S, Pal A, et al. (2016) Cu-Chitosan Nanoparticle Mediated Sustainable Approach To Enhance Seedling Growth in Maize by Mobilizing Reserved Food. J Agric and Food Chem 64(31): 6148-6155.

11. Zheng L, Hong F, Lu S, Liu C (2005) Effect of nano-TiO2 on strength of naturally aged seeds and growth of spinach. Biol Trace Elem Res 104(1): 83-92.

12. Schmiele M, Busch S, Morhenn H, Schindler T, Schmutzler T, et al. (2016) Structural Characterization of Lecithin-Stabilized Tetracosane Lipid Nanoparticles. Part II: Suspensions. J Phys Chem B 120(24): 5513-5526.

13. Dimpka CO, McLean JE, Latta DE, Manangón E, Britt DW, et al. (2012) $\mathrm{CuO}$ and $\mathrm{ZnO}$ nanoparticles: phytotoxicity, metal speciation, and induction of oxidative stress in sand-grown wheat. J Nanopart Res 14(9): 1125.

14. Wang Q, Ma X, Zhang W, Pei H, Chen Y (2012) The impact of cerium oxide nanoparticles on tomato (Solanum lycopersicum L.) and its implications for food safety. Metallomics 4(10): 1105-1112.

15. Schwab F, Zhai G, Kern M, Turner A, Schnoor JL, et al. (2016) Barriers, pathways and processes for uptake, translocation and accumulation of nanomaterials in plants-Critical review. Nanotoxicology 10(3): 257278.

16. Zhu H, Han J, Xiao JQ, Jin Y (2008) Uptake, translocation, and accumulation of manufactured iron oxide nanoparticles by pumpkin plants. J Environ Monit 10(6): 713-717.

17. Birbaum K, Brogioli R, Schellenberg M, Martinoia E, Stark WJ, et al. (2010) No evidence for cerium dioxide nanoparticle translocation in maize plants. Environ Sci \&Technol 44(22): 8718-8723.

18. Akagi T, Kaneko T, Kida T, Akashi M (2005) Preparation and characterization of biodegradable nanoparticles based on poly 
( $\gamma$-glutamic acid) with L-phenylalanine as a protein carrier. J Control Release 108(2): 226-236.

19. Lai F, Wissing SA, Müller RH, Fadda AM (2006) Artemisia arborescens L. essential oil-loaded solid lipid nanoparticles for potential agricultural application: preparation and characterization. AAPS Pharm Sci Tech 7(1): E2.

20. Zargar SM, Nazir M, Agrawal GK, Kim DW, Rakwal R (2010) Silicon in plant tolerance against environmental stressors: towards crop improvement using omics approaches. Curr Proteomics 7(2): 135-143.

21. Wang X, Su Y, Liu Y, Kim SC, Fanella B (2014) Phosphatidic acid as lipid messenger and growth regulators in plants. Phospholipases in Plant Signaling, Springer, Berlin Heidelberg, Germany, pp. 69-92.

22. Taha RA, Hassan MM, Ibrahim EA, Baker NHA, Shaaban EA (2016) Carbon nanotubes impact on date palm in vitro cultures. PCTOC Plant Cell Tissue Organ Cult 127(2): 525-534.

23. Lee WM, Kwak JI, An YJ (2012) Effect of silver nanoparticles in crop plants Phaseolus radiatus and Sorghum bicolor: media effect on phytotoxicity. Chemosphere 86(5): 491-499.
24. Joseph S, Graber ER, Chia C, Munroe P, Donne S, et al. Shifting paradigms: development of high-efficiency biochar fertilizers based on nanostructures and soluble components. Carbon Manage 4(3): 323-343.

25. Yu EQ (2005) U.S. Patent No. 6,942,714, Patent and Trademark Office, Washington, DC, USA.

26. Keresztessy Z, Bodnár M, Ber E, Hajdu I, Zhang M, et al. (2009) Selfassembling chitosan/poly-g-glutamic acid nanoparticles for targeted drug delivery. Colloid Polymer Sci 287(7): 759-765.

27. Akagi T, Baba M, Akashi M (2011) Biodegradable nanoparticles as vaccine adjuvants and delivery systems: regulation of immune responses by nanoparticle-based vaccine. In Polymers in nanomedicine, Springer, Springer Berlin Heidelberg, Germany, pp. 31-64.

28. Uto T, Akagi T, Yoshinaga K, Toyama M, Akashi M, et al. (2011) The induction of innate and adaptive immunity by biodegradable poly $(\gamma$-glutamic acid) nanoparticles via a TLR4 and MyD88 signaling pathway. Biomaterals 32(22): 5206-5212.

\begin{tabular}{|l|}
\hline \multicolumn{1}{|c|}{ Your next submission with Juniper Publishers } \\
will reach you the below assets \\
- Quality Editorial service \\
- Swift Peer Review \\
- Reprints availability \\
- E-prints Service \\
- Manuscript Podcast for convenient understanding \\
- Global attainment for your research \\
- Manuscript accessibility in different formats \\
( Pdf, E-pub, Full Text, Audio) \\
- Unceasing customer service \\
Track the below URL for one-step submission \\
https://juniperpublishers.com/online-submission.php \\
\hline
\end{tabular}

